4. Lau, C.P. Attempted suicide with enalapril. $N$ Engl J Med 1986, 315: 197.

5. Varughese, A., Taylor, A.A. \& Nelson, E.B. Consequences of angiotensin converting enzyme inhibitor overdose. Am J Hypertens 1989, 2: 355-357.

6. Dawson, A.H., Harvey, D., Smith, A.J. et al. Lisinopril overdose. Lancet 1990, 335: 487-488.

7. Ajavi, A.A., Campbell, B.C., Rubin, P.C. et al. Effects of naloxone on the actions of captopril. Clin Pharmacol Ther 1985, 38: $560-565$.

\section{Percutaneous endoscopic gastrostomy in elderly patients}

Sir,

I read 'Percutaneous endoscopic gastrostomy in elderly patients" with interest. I was surprised the authors did not mention percutaneous non-endoscopic gastrostomy, which is probably the best method of gastrostomy for enteral feeding. The technique was first described independently by three radiologists in $1983 .^{2-4}$ The stomach is initially inflated with air via a nasogastric tube. The stomach is located by fluoroscopy and the feeding tube is introduced under local anaesthesia using the Seldinger technique.

The technique has a number of advantages over percutaneous endoscopic gastrostomy: (1) It can be performed quickly and easily by one operator without the need for endoscopy, intravenous sedation or general anaesthesia; (2) it is simple and can be learned more easily as it does not require endoscopy skills; (3) because the feeding tube is introduced percutaneously under sterile technique rather than via the oesophagus, the incidence of wound infection and aspiration is much lower; (4) a larger tube can be placed, permitting easier feeding of the patient; (5) the technique can be used even in the presence of severe oesophageal narrowing; (6) it is easier to change the tube when it becomes obstructed; (7) it is easier to advance the tube into the jejunum if required. ${ }^{5}$

The largest series to date reports a procedure-related mortality of $0.8 \%$ and a major complication rate of $1.2 \%$ which compares favourably with the figures quoted for percutaneous endoscopic gastrostomy. ${ }^{5}$ Percutaneous gastrostomy using the Seldinger technique would therefore appear to be the preferred method of gastrostomy for enteral feeding.

V.G.M. McDermott $X$-Ray Department, Royal Infirmary,

1 Lauriston Place, Edinburgh EH3, UK.

\section{References}

1. Finucane, P., Aslan, S.M. \& Duncan, D. Percutaneous endoscopic gastrostomy in elderly patients. Postgrad Med J 1991, 67: $371-373$.

2. Will, J.S. \& Ogelsby, J.T. Percutaneous gastrostomy. Radiology 1983, 149: 449-453.

3. Ho, C.S., Gray, R.R., Goldfinger, M., Rosen, I.E. \& McPherson, R. Percutaneous gastrostomy for jejunal feeding. Radio$\log y$ 1983, 149: 595-596.

4. Tao, H.H. \& Gillies, R.R. Percutaneous feeding gastrostomy.응 A J R 1983, 141: 793-794.

5. Halkier, B.K., Ho, C.S. \& Yee, A.C.N. Percutaneous feedingē gastrostomy with the Seldinger technique: review of 2527 patients. Radiology 1989, 171: 359-362. 